\title{
Preface: Andean Patagonian lakes as sensors of global change
}

\author{
Beatriz E. Modenutti $\bullet$ Esteban G. Balseiro
}

Received: 2 April 2018/Revised: 2 April 2018/Accepted: 17 April 2018/Published online: 30 April 2018

(C) Springer International Publishing AG, part of Springer Nature 2018

The main idea underlying this special section in Hydrobiologia was to develop a compiled work of Andean Patagonian lakes in relation to climate change. The particular location of Patagonian lakes can provide valuable information about patterns and mechanisms on how global climate change is altering ecosystems. Patagonia is located at the southern end of South America comprising the southern section of the Andes, including the largest glaciered area in South America, as well as deserts, steppes and grasslands to the east towards the Atlantic Ocean.

This special section includes a collection of eight papers focusing on different topics and approaches. Two papers include extensive surveys of Patagonian lakes; the paper by Coviaga et al. analyses ostracods distribution in 40 aquatic environments and discusses their value as biological proxies of environmental change, while Becker et al. review data of Patagonian fishes and explore their future distribution in the context of climate change. Three contributions analyse

Guest editors: Beatriz E. Modenutti \& Esteban G. Balseiro / Andean Patagonian Lakes as Sensor of Global Change

B. E. Modenutti · E. G. Balseiro ( $₫)$

INIBIOMA (CONICET-UNComahue), Bariloche,

Argentina

e-mail: e.balseiro@comahue-conicet.gob.ar

B. E. Modenutti

e-mail: bmodenutti@comahue-conicet.gob.ar a particular ecological process related with global climate change in a lake. The paper by Bastidas et al. evaluates, based on a temporal dataset, the effect of changes in sediment inputs, coming from melting glaciers, on water transparency and deep chlorophyll maximum development in the deep Lake Mascardi. Baffico et al. examine the naturally extremely acidic Lake Caviahue and discuss its value as a sentinel of changes in nutrient atmospheric deposition. Valiñas et al. experimentally determine the combined effect of nutrient, acidification and solar radiation in a planktonic food web of a Patagonian steppe lake. Only one study provides data on paleolimnology; the paper by Massaferro et al. analyses chironomid assemblages in two mountain lakes, discussing the main drivers of faunal changes. Two papers compare Patagonian lakes with other aquatic systems. Torremorell et al. study the importance of phosphorus and light for phytoplankton communities, comparing shallow lakes from the Argentinean Pampas and Patagonia. Finally, the paper by Villar Argaiz et al. analyses the resource versus consumer regulation of phytoplankton, comparing two experiments carried out in North and South Hemisphere lakes.

We thank Hydrobiologia Editor-in-Chief, Prof Dr Martens and Associate Editor-in-Chief Dr Thomaz, for supervising the whole editorial process, giving us the opportunity to edit this collection of papers and also thanks to all the referees that have thoroughly 
reviewed these manuscripts. We sincerely hope that such a set of papers will be of interest for a broad scientific audience and will encourage new ideas and new research programs on these overlooked water bodies. 